\title{
Mutational profiling of brain metastasis from breast cancer: matched pair analysis of targeted sequencing between brain metastasis and primary breast cancer
}

\author{
Ji Yun Lee ${ }^{1, *}$, Kyunghee Park ${ }^{2, *}$, Sung Hee Lim¹, Hae Su Kim¹, Kwai Han Yoo ${ }^{1}$, Ki \\ Sun Jung ${ }^{1}$, Haa-Na Song ${ }^{1}$, Mineui Hong ${ }^{3}$, In-Gu Do ${ }^{3}$, Taejin Ahn' ${ }^{2}$, Se Kyung Lee ${ }^{4}$, \\ Soo Youn Bae ${ }^{4}$, Seok Won Kim ${ }^{4}$, Jeong Eon Lee ${ }^{4}$, Seok Jin Nam ${ }^{4}$, Duk-Hwan Kim ${ }^{5}$, \\ Hae Hyun Jung ${ }^{6}$, Ji-Yeon Kim ${ }^{1}$, Jin Seok Ahn ${ }^{1}$, Young-Hyuck Im ${ }^{1}$, Yeon Hee Park ${ }^{1}$ \\ ${ }^{1}$ Division of Hematology-Oncology, Department of Medicine, Samsung Medical Center, Sungkyunkwan University School of \\ Medicine, Seoul, Korea \\ ${ }^{2}$ Samsung Genomic Institute, Samsung Biological Research Institute, Samsung Medical Center, Sungkyunkwan University \\ School of Medicine, Seoul, Korea \\ ${ }^{3}$ Center of Companion Diagnostics, Innovative Cancer Medicine Institute, Samsung Medical Center, Sungkyunkwan University \\ School of Medicine, Seoul, Korea \\ ${ }^{4}$ Department of Surgery, Samsung Medical Center, Sungkyunkwan University School of Medicine, Seoul, Korea \\ ${ }^{5}$ Department of Molecular Cell Biology, Samsung Biomedical Research Institute, Sungkyunkwan University School of \\ Medicine, Suwon, Korea \\ ${ }^{6}$ Biomedical Research Institute, Samsung Medical Center, Sungkyunkwan University School of Medicine, Seoul, Korea \\ *These authors have contributed equally to this work
}

Correspondence to: Yeon Hee Park, e-mail: yhparkhmo@skku.edu

Keywords: breast cancer, brain metastasis, gene, mutation, mechanism

Received: August 27, 2015

Accepted: October 06, 2015

Published: October 20, 2015

\section{ABSTRACT}

Although breast cancer is the second most common cause of brain metastasis with a notable increase of incidence, genes that mediate breast cancer brain metastasis (BCBM) are not fully understood. To study the molecular nature of brain metastasis, we performed gene expression profiling of brain metastasis and matched primary breast cancer (BC). We used the Ion AmpliSeq Cancer Panel v2 covering 2,855 mutations from 50 cancer genes to analyze 18 primary BC and 42 BCBM including 15 matched pairs. The most common ВСВM subtypes were triple-negative $(42.9 \%)$ and basal-like (36.6\%). In a total of 42 BCBM samples, $32(76.2 \%)$ harbored at least one mutation (median 1, range 0-7 mutations). Frequently detected somatic mutations included TP53 (59.5\%), MLH1 (14.3\%), PIK3CA (14.3\%), and KIT (7.1\%). We compared BCBM with patient-matched primary BC specimens. There were no significant differences in mutation profiles between the two groups. Notably, gene expression in BCBM such as TP53, PIK3CA, KIT, MLH1, and RB1 also seemed to be present in primary breast cancers. The TP53 mutation frequency was higher in BCBM than in primary BC $(59.5 \%$ vs $38.9 \%$, respectively). In conclusion, we found actionable gene alterations in BCBM that were maintained in primary BC. Further studies with functional testing and a delineation of the role of these genes in specific steps of the metastatic process should lead to a better understanding of the biology of metastasis and its susceptibility to treatment. 


\section{INTRODUCTION}

Breast cancer $(\mathrm{BC})$ is the second-most common cancer that spreads to the brain [1]. The prevalence of breast cancer brain metastasis (BCBM) has been reported to range from $10-16 \%$, reaching $30 \%$ when autopsy diagnoses of brain metastasis are included $[1,2]$. The median survival after development of BCBM is approximately 4-5 months [3]. Breast cancer patients with triple-negative (TN), basal-like, HER2-positive tumors are at the highest risk of brain cancer relapse [4-6]. However, the molecular basis of mechanisms responsible for BM remains elusive because the brain is a special challenge for tumor cells due to the blood-brain barrier (BBB).

Organ-specific metastasis has been associated with a set of genes that are involved in metastatic processes such as tumor cell intravasation, survival in circulation, extravasation into a distant organ, angiogenesis and uninhibited growth $[7,8]$. Most research regarding BCBM development has been based on gene expression profiling of $\mathrm{BC}$ coupled with clinical data, functional analysis on cell lines, and in vivo animal models [9-11]. Recently, there have been many studies on the gene expression profile of BCBM compared to their matched primary BC. Silva et al. suggests that increased activation of $H E R 3$ and its downstream MAPK/AKT pathway molecules are implicated in colonization of brain metastasis [12]. Bolling-Fischer et al. showed the amplified oncogenes including SOX2, PIK3CA, NTRK1, GNAS, CTNNB1, and FGFR1 are related to the Stem Cell Pluripotency pathway [13]. Saunus et al. identified novel candidates with possible roles in BCBM development including the significantly mutated genes $D S C 2, S T 7, P I K 3 R 1$, and SMC5 [14]. However, the clinical relevance of many existing candidates is not fully understood. Therefore, we aim to identify genes that are correlated with the propensity of primary $\mathrm{BC}$ to brain cancer relapse using matched tissue samples from BCBM and primary BC.

\section{RESULTS}

\section{Patient characteristics}

Patient demographics are summarized in Table 1. Median age at diagnosis of $\mathrm{BC}$ was 45 years. The majority of patients were premenopausal woman (79.5\%) and the most common histology was invasive ductal carcinoma (88.1\%). Five (11.9\%) patients were initially diagnosed as stage IV metastatic disease. Among 45 patients, the proportion of ER+, ER+/HER2+, HER2+, and TNBC in breast cancer tissue was $31.7 \%, 9.8 \%, 26.8 \%$, and $31.7 \%$, respectively. The median time to brain metastasis from curative resection and median overall survival from BCBM was 2.5 years (range, $0-17.7$ years) and 1.9 years (range, 0.3-6.7 years), respectively. Among the $42 \mathrm{BCBM}$ samples, the distribution by tumor subtype according to the immunohistochemistry (IHC) included $42.9 \%$ TN, 26.2\% ER+, 19.0\% HER2+, and 11.9\% ER+/HER2+ type (Table 1). In the same group, PAM50 subtypes included 36.6\% basal-like, 31.7\% Her2-enriched, 29.3\% luminal (A or B), and 2.4\% normal-like type (Table 1).

\section{Mutation analysis using the Iron AmpliSeq cancer panel $(\mathrm{MAF}>\mathbf{0 . 1})$}

To identify patterns of gene expression associated with BCBM, we performed a NGS using the Iron AmpliSeq cancer panel. In total, we obtained 3898 variant calls from 60 samples and 97 variant calls were selected: 25 variant calls with 23 mutations for primary $\mathrm{BC}$ and 72 variant calls with 64 mutations for BCBM (Figure 1). The most common genetic alterations were somatic single nucleotide variants (SNVs) $(82 / 97,84.5 \%)$ and small insertion-deletions (indels) (12/97, 12.4\%). Although there were no significant differences in mutation type according to the tumor tissue, proportion of SNVs was numerically higher in primary BC group $(96.0 \%$ vs $80.6 \%$, $P=0.187$ ). Detailed frequency of mutations and amino acid changes in 60 samples are described in Table S2.

Figure 2 shows the frequency of mutations in 50 genes among 60 patients according to the tissue origin. The frequency of mutations was not significantly different between primary $\mathrm{BC}$ and $\mathrm{BCBM}(P=0.475)$. When using the 50 -cancer gene panel in 18 primary BC samples, 14 of 18 patients $(77.8 \%)$ had at least one mutation (median 1, range 0-4 mutations). Among the 23 mutations in primary $\mathrm{BC}$, the frequency of mutations according to subtype was as follows: TN (43.5\%), ER+ (34.8\%), HER2+ (21.7\%), and ER+/HER2+ $(0 \%)$ for IHC and luminal A (39.1\%), HER2-enriched (34.8\%), and basal-like (26.1\%) for PAM50 (Table S3). Among the 18 primary $\mathrm{BC}$ cases, the most common mutations included TP53 (7, 38.9\%), RBI (4, 22.2\%), SMAD4 (3, 16.7\%), MLH1 (2, 11.1\%), PIK3CA $(2,11.1 \%)$, and $\operatorname{KIT}(2,11.1 \%)$.

In a total of $42 \mathrm{BCBM}$ samples, $32(76.2 \%)$ harbored at least one mutation (median 1, range 0-7 mutations). Among the 64 mutations in BCBM, the frequency of mutation according to the subtypes was as follows: TN (39.1\%), ER+ (32.8\%), HER2+ (17.2\%), and ER+/ HER 2+ $(10.9 \%)$ for IHC and basal-like (31.3\%), luminal B (26.6\%), HER2-enriched (25.0\%), luminal A (15.6\%) and normal-like (1.5\%) for PAM50 (Table S3). Among the 42 BM cases, TP53 was the most common mutation (25, 59.5\%). Other mutations included MLH1 (6, 14.3\%), PIK3CA (6, 14.3\%), and KIT (3, 7.1\%). Figure 3 depicts the heat map of the mutations detected in the 60 samples.

Among the 30 TP53 mutations detected in BCBM, $25(83.3 \%)$ occurred in exons 5-8, which is the DNA binding domain (Table S4). The majority of TP53 mutations were missense mutations $(15,50.0 \%)$. Other alterations included frameshift insertion/deletions 
Table 1: Baseline characteristics

\begin{tabular}{|c|c|c|c|c|}
\hline \multicolumn{3}{|c|}{ 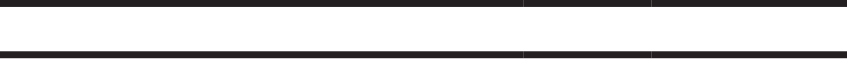 } & $N=45$ & $\%$ \\
\hline \multicolumn{3}{|c|}{ Median age (range), years } & \multicolumn{2}{|c|}{$44.6(22.4-64.1)$} \\
\hline \multicolumn{3}{|c|}{ Menopausal status } & & \\
\hline \multicolumn{3}{|l|}{ Premenopausal } & 31 & 79.5 \\
\hline \multicolumn{3}{|c|}{ Postmenopausal } & 8 & 20.5 \\
\hline \multicolumn{5}{|c|}{ Histology } \\
\hline \multicolumn{3}{|c|}{ Invasive ductal carcinoma } & 37 & 88.1 \\
\hline \multicolumn{3}{|c|}{ Invasive lobular carcinoma } & 1 & 2.4 \\
\hline \multicolumn{3}{|c|}{ Others } & 4 & 9.5 \\
\hline \multicolumn{5}{|l|}{ Grade } \\
\hline \multicolumn{3}{|l|}{ Low } & 0 & 0 \\
\hline \multicolumn{3}{|l|}{ Intermediate } & 11 & 34.4 \\
\hline \multicolumn{3}{|l|}{ High } & 21 & 65.6 \\
\hline \multicolumn{5}{|l|}{ Stage } \\
\hline \multicolumn{3}{|l|}{ I } & 7 & 16.7 \\
\hline \multicolumn{3}{|l|}{ II } & 17 & 40.5 \\
\hline \multicolumn{3}{|l|}{ III } & 13 & 31.0 \\
\hline \multicolumn{3}{|l|}{ IV } & 5 & 11.9 \\
\hline \multicolumn{3}{|c|}{ Median time to brain metastasis (range) ${ }^{*}$, years } & \multicolumn{2}{|c|}{$2.5(0-17.7)$} \\
\hline \multicolumn{3}{|c|}{ Median overall survival (range) ${ }^{\dagger}$, years } & \multicolumn{2}{|c|}{$5.1(0.8-20.0)$} \\
\hline \multirow[t]{2}{*}{ Subtype } & \multicolumn{2}{|c|}{ Breast $(N=18)$} & \multicolumn{2}{|c|}{ Brain $(N=42)$} \\
\hline & $N$ & $\%$ & $N$ & $\%$ \\
\hline \multicolumn{5}{|l|}{$\mathrm{IHC}$} \\
\hline ER+ & 5 & 27.8 & 11 & 26.2 \\
\hline ER+/HER2+ & 0 & 0 & 5 & 11.9 \\
\hline HER 2+ & 6 & 33.3 & 8 & 19.0 \\
\hline $\mathrm{TN}$ & 7 & 38.9 & 18 & 42.9 \\
\hline \multicolumn{5}{|l|}{ PAM50 } \\
\hline Luminal A & 6 & 33.3 & 4 & 9.8 \\
\hline Luminal B & 0 & 0 & 8 & 19.5 \\
\hline Her2-enriched & 6 & 33.3 & 13 & 31.7 \\
\hline Basal-like & 5 & 27.8 & 15 & 36.6 \\
\hline Normal-like & 1 & 5.6 & 1 & 2.4 \\
\hline
\end{tabular}

*median time to brain metastasis from curative resection 'median overall survival from brain metastasis

$(8,26.7 \%)$, nonsense mutations (4, 13.3\%), splicing $(2,6.7 \%)$, and in-frame insertion/deletions (1, 3.3\%). Frameshift, splicing, and nonsense mutations and inframe insertions and deletions constitute complex TP53 mutations [15]. In terms of the PAM50 subtype, complex mutations were observed in HER2-enriched $(8 / 15,53.3 \%)$ and basal-like $(7 / 15,46.7 \%)$.

\section{Comparison between breast cancer and brain metastasis}

Tumor progression is considered the result of cumulative oncogenic alterations. We hypothesized that tissue-specific genes for metastasis are superimposed on the breast gene expression signature. We compared 


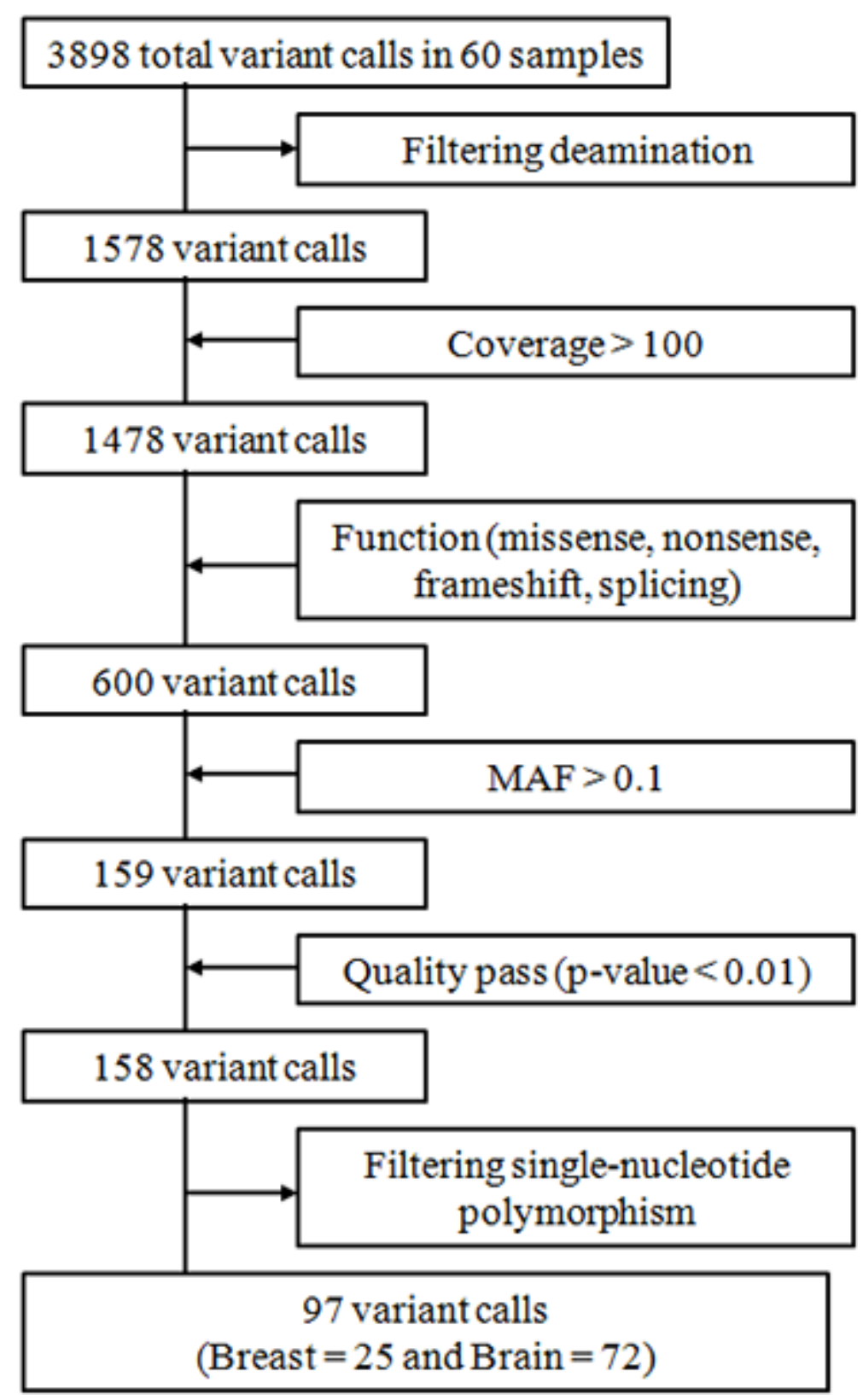

Figure 1: Summary of variant call processing. 

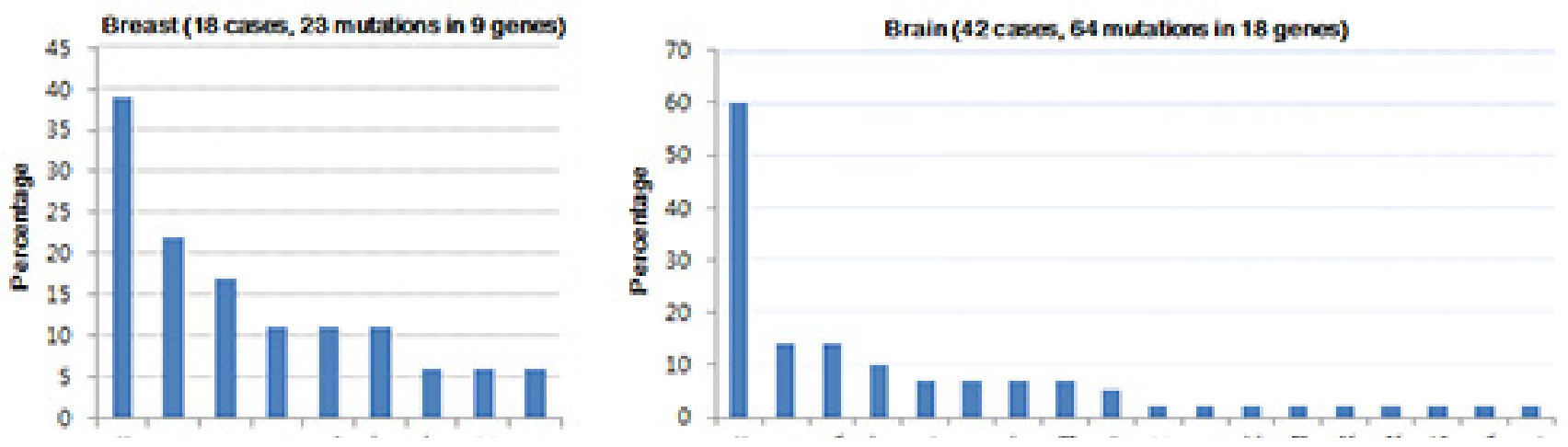

Figure 2: Frequency of mutations in 60 patients for Ampliseq (MAF > 0.1). (a) primary breast cancer and (b) brain metastasis from the breast.

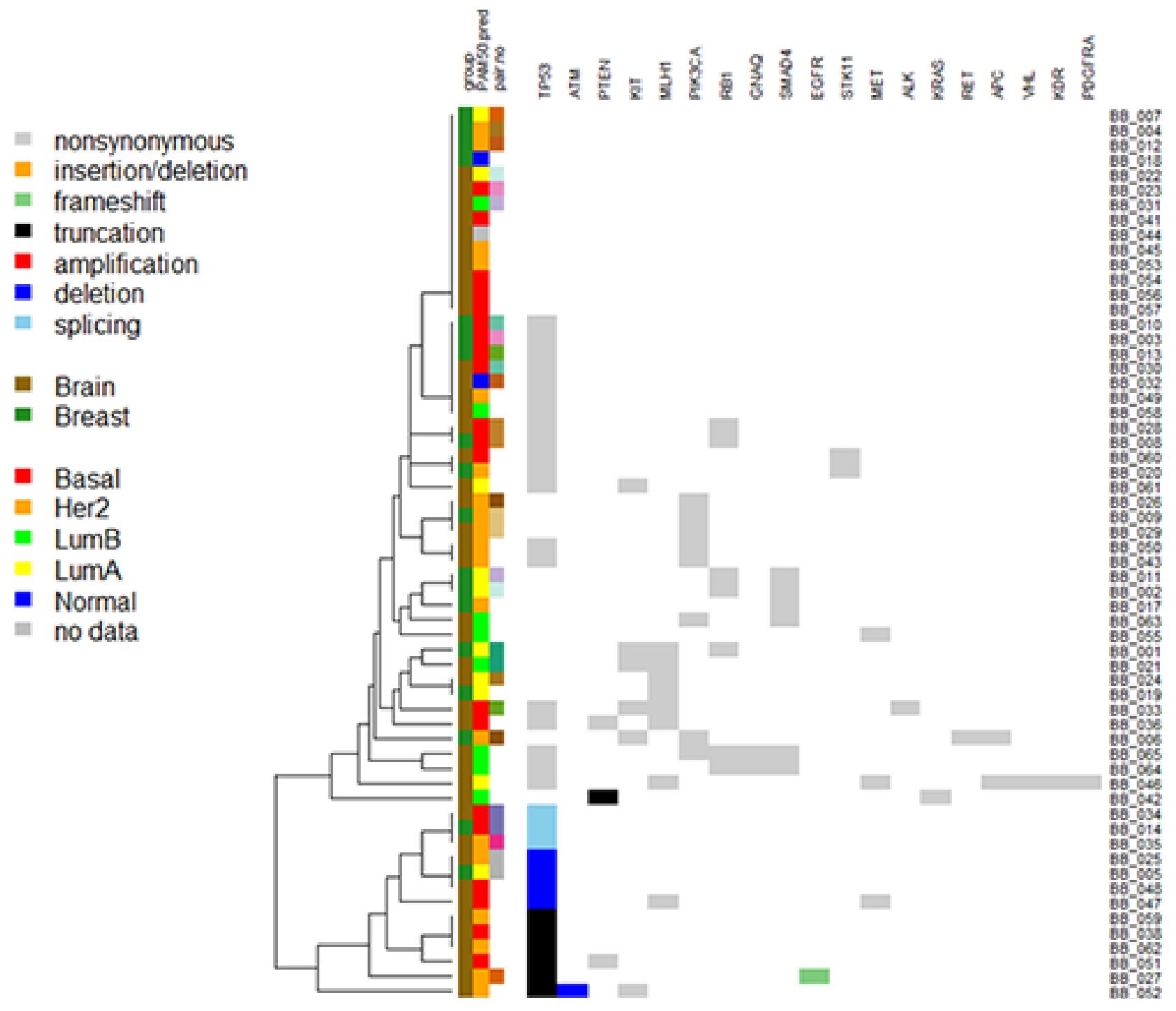

Figure 3: Heatmap of the mutations found in 60 patients. 
Table 2: Comparison of mutation profiles using Ampliseq (MAF $>0.1$ )

\begin{tabular}{|c|c|c|c|c|c|c|c|c|c|}
\hline Data set & $\begin{array}{c}\text { Group } 1 \text { vs } \\
\text { Group } 2\end{array}$ & Gene & $\begin{array}{c}\text { Group } 1 \\
\text { wild }\end{array}$ & $\begin{array}{c}\text { Group } 1 \\
\text { mut }\end{array}$ & $\begin{array}{c}\text { Group } 2 \\
\text { wild }\end{array}$ & $\begin{array}{c}\text { Group } 2 \\
\text { mut }\end{array}$ & $P$ value & $\begin{array}{c}\text { Group } 1 \\
\text { ratio }\end{array}$ & $\begin{array}{c}\text { Group 2 } \\
\text { ratio }\end{array}$ \\
\hline \multirow{2}{*}{$\begin{array}{c}\text { All } \\
(N=60)\end{array}$} & \multirow{2}{*}{$\begin{array}{c}\text { Brain } v s \\
\text { Breast }\end{array}$} & TP53 & 17 & 25 & 11 & 7 & 0.167 & 0.5952 & 0.3889 \\
\hline & & RB1 & 39 & 3 & 14 & 4 & 0.182 & 0.0714 & 0.2222 \\
\hline \multirow{2}{*}{$\begin{array}{c}\text { Pair } \\
(N=15)\end{array}$} & \multirow{2}{*}{$\begin{array}{c}\text { Brain } v s \\
\text { Breast }\end{array}$} & RB1 & 14 & 1 & 11 & 4 & 0.330 & 0.0667 & 0.2667 \\
\hline & & SMAD4 & 15 & 0 & 13 & 2 & 0.483 & 0 & 0.1333 \\
\hline
\end{tabular}

mutation profiles of primary $\mathrm{BC}(N=18)$ and $\mathrm{BCBM}$ $(N=42)$ in order to identify gene expression signatures associated with BM. There was no significant difference in mutation profiles between the two groups (Table 2). $R B 1$ mutations were found in $3(7.1 \%)$ and 4 cases $(22.2 \%)$ in the $\mathrm{BM}$ and $\mathrm{BC}$ groups, respectively $(P=0.182)$. Next, we explored the patient-matched pair samples with primary BC and BCBM. Discordant expression of PAM50 molecular subtypes and IHC was observed between primary BC and BCBM (Table S5). A PAM50 molecular subtype conversion was observed in 7/15 (46.7\%). In IHC, $2 / 15$ (13.3\%) paired cases had discordant ER expression, all of which were loss of ER. Genetic alterations such as TP53, PIK3CA, KIT, MLH1, and $R B 1$ were detected in both primary $\mathrm{BC}$ and $\mathrm{BCBM}$ in the same patients (Figure 4). $R B 1$ mutations were observed more frequently in primary $\mathrm{BC}$ samples than in $\mathrm{BCBM}$ samples $(26.7 \%$ vs $7.1 \%, P=0.330)$. SMAD4 mutations were identified in 2 cases (13.3\%) among 15 primary BC samples, but no mutation was observed in BCBM samples. In all 15 pairs, 5 pairs including $\# 5, \# 8, \# 9, \# 10$ and $\# 14$ had identical genetic alterations. Three paired sets (\#1, $\# 6$, and \#13) demonstrated a set of conserved cancer gene aberrations, though two sets showed additional cancer gene lesions in the primary $\mathrm{BC}$ and the other had gains in the BCBM. In pair \#6, 4 mutations including $A P C, K I T$, $P I K 3 C A$, and $R E T$ were detected in the primary lesion, but only the PIK3CA mutation was detected in the BCBM.

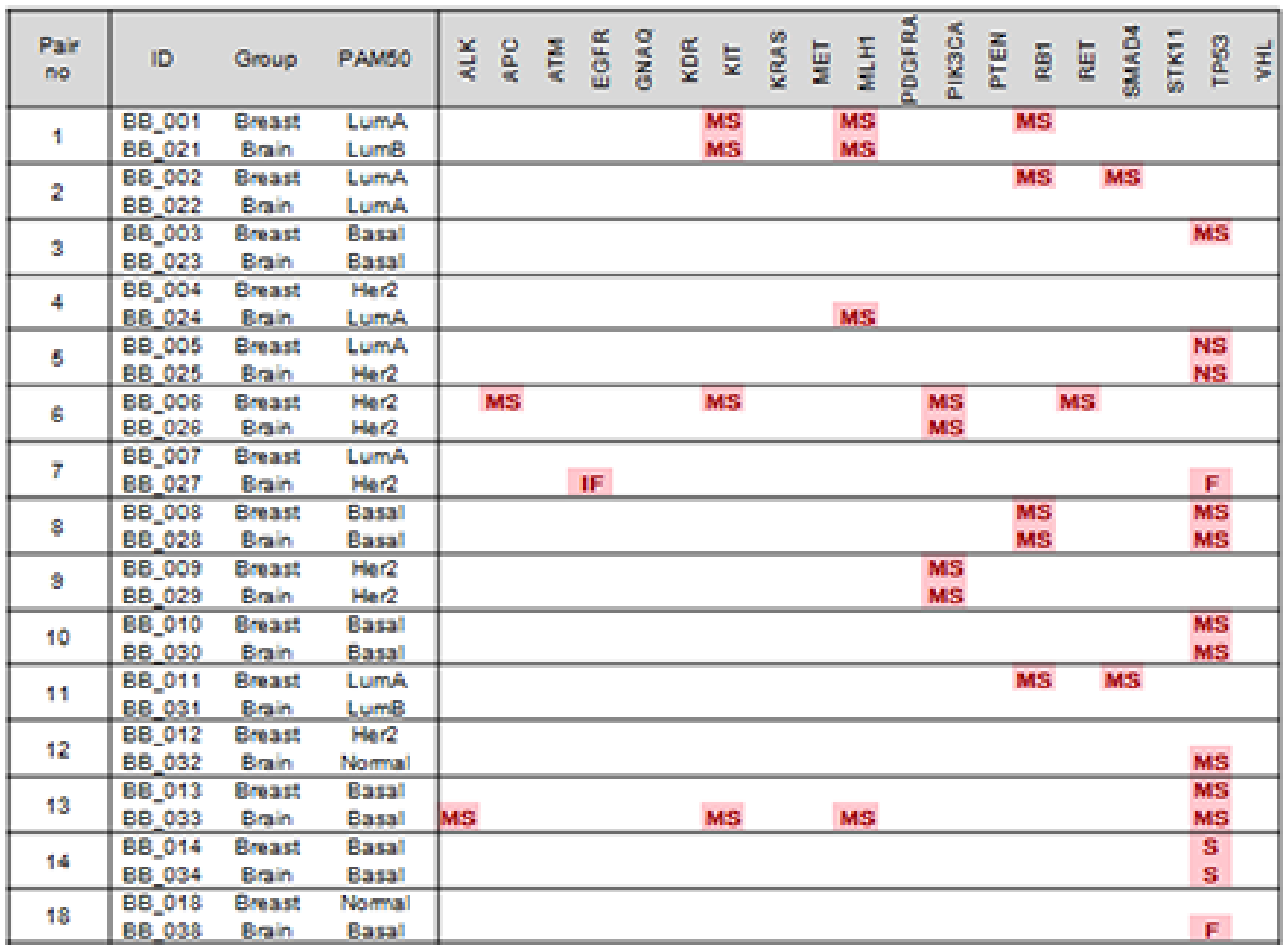

Figure 4: Gene expression profiles of the primary breast cancer were compared to those of brain metastasis from breast cancer (MS, missense; NS, non-sense; F, frameshift; IF, in-frame insertion/deletion; S, splicing). 
Table 3: TP53 mutations in brain metastasis with matched primary breast cancer ( 9 pairs, 8 mutations in bain; 6 mutations in breast)

\begin{tabular}{|c|c|c|c|c|c|c|c|}
\hline $\begin{array}{l}\text { Pair } \\
\text { No. }\end{array}$ & Case No. & Tissue & IHC & PAM50 & coding & Function & Protein \\
\hline \multirow{2}{*}{3} & BB_003 & Breast & $\mathrm{TN}$ & Basal & c. $535 \mathrm{C}>\mathrm{T}$ & [missense] & p.His179Tyr \\
\hline & BB_023 & Brain & $\mathrm{TN}$ & Basal & & & \\
\hline \multirow{2}{*}{5} & BB_005 & Breast & $\mathrm{ER}+$ & LumA & c. $497 \mathrm{C}>\mathrm{G}$ & [nonsense] & p.Ser166* \\
\hline & BB_025 & Brain & ER+ & Her2 & c. $497 \mathrm{C}>\mathrm{G}$ & [nonsense] & p.Ser166* \\
\hline \multirow{2}{*}{7} & BB_007 & Breast & $\mathrm{ER}+$ & LumA & & & \\
\hline & BB_027 & Brain & $\mathrm{TN}$ & Her2 & c.1013_1014insCGAGA & [frameshiftInsertion] & p.Met340Thr \\
\hline \multirow{2}{*}{8} & BB_008 & Breast & $\mathrm{TN}$ & Basal & c. $584 \mathrm{~T}>\mathrm{C}$ & [missense] & p.Ile195Thr \\
\hline & BB_028 & Brain & $\mathrm{TN}$ & Basal & c. $584 \mathrm{~T}>\mathrm{C}$ & [missense] & p.Ile195Thr \\
\hline \multirow{2}{*}{10} & BB_010 & Breast & $\mathrm{TN}$ & Basal & c. $838 \mathrm{~A}>\mathrm{G}$ & [missense] & p.Arg280Gly \\
\hline & BB_030 & Brain & $\mathrm{TN}$ & Basal & c. $838 \mathrm{~A}>\mathrm{G}$ & [missense] & p.Arg280Gly \\
\hline \multirow{2}{*}{12} & BB_012 & Breast & HER2+ & Her2 & & & \\
\hline & BB_032 & Brain & HER2+ & Normal & c. $770 \mathrm{~T}>\mathrm{G}$ & [missense] & p.Leu257Arg \\
\hline \multirow{2}{*}{13} & BB_013 & Breast & $\mathrm{TN}$ & Basal & c. $329 \mathrm{G}>\mathrm{C}$ & [missense] & p.Arg110Pro \\
\hline & BB_033 & brain & $\mathrm{TN}$ & Basal & c. $535 \mathrm{C}>\mathrm{T}$ & [missense] & p.His179Tyr \\
\hline \multirow{2}{*}{14} & BB_014 & Breast & $\mathrm{TN}$ & Basal & $\operatorname{chr} 17: 7577610 \mathrm{~T}>\mathrm{C}$ & splicing & \\
\hline & BB_034 & Brain & $\mathrm{TN}$ & Basal & $\operatorname{chr} 17: 7577610 \mathrm{~T}>\mathrm{C}$ & splicing & \\
\hline \multirow{2}{*}{18} & BB_018 & Breast & $\mathrm{TN}$ & Normal & & & \\
\hline & BB_038 & brain & $\mathrm{TN}$ & Basal & c.1024_1024delC & [frameshiftDeletion] & p.Arg342Glu \\
\hline
\end{tabular}

On the other hand, in pair \#13, only a TP53 mutation was observed in primary $\mathrm{BC}$, but 4 mutations, $A L K, K I T$, $M L H 1$, and TP53, were observed in the BCBM.

\section{Analysis of paired primary breast and brain metastasis}

Next, we aimed to identify candidate TP53 mutations with possible roles in BC development. To explore the molecular differences of TP53 between primary $\mathrm{BC}$ and $\mathrm{BCBM}$, we compared the TP53 gene expression profiles of $\mathrm{BCBM}$ to matched primary $\mathrm{BC}$ (Table 3). In all 9 pairs, 4 pairs including $\# 5, \# 8, \# 10$, and \#14 had identical TP53 mutations. In pair \#3, His179Tyr was observed in breast cancer, but no His179Tyr mutation was observed in brain metastasis. In 3 pairs, the TP53 mutation was detected in BCBM, but no mutation was observed in the primary BC: Met340Thr (frameshift insertion) for \#7, Leu257Arg (missense) for \#12, and Arg342Glu (frameshift deletion) for \#18.

\section{DISCUSSION}

Current therapeutic strategies for BCBM include whole brain radiation therapy, stereotactic radiosurgery, and surgery combined with radiotherapy [16, 17]. Recently, systemic treatments such as chemotherapy and targeted therapy after local therapy improved survival in patients with BCBM $[18,19]$. Nevertheless, BCBM has limited life expectancy since chemotherapeutic and targeted agents penetrate the BBB. In the whole genome sequencing era, genomic and transcriptomic analysis may uncover new drug agents targeting BCBM. However, studies of genetic alterations in BCBM have been limited by the lack of tissue availability. To the best our knowledge, this is the largest study to demonstrate the gene expression profiles of brain metastasis and matched primary breast cancer using targeted sequencing.

We performed genome-wide aberration profiling on 18 primary $\mathrm{BC}$ and $42 \mathrm{BCBM}$ tissue samples and compared the properties of mutations between these two tumor groups. The set of BCBM samples was enriched for $\mathrm{TN} /$ basal-like $\mathrm{BC}$, which is consistent with previous reports of an increased propensity of metastasis to the brain $[5,20]$. Furthermore, the frequency of genetic alterations was closely linked to subtype in BCBM. We found that $76.2 \%$ of $\mathrm{BCBM}$ patients harbored at least one mutation. Known mutated drivers of primary breast were frequently mutated in BCBM including TP53, MLH1, PIK3CA, and KIT. When we analyzed matched pairs 
of primary $\mathrm{BC}$ and $\mathrm{BCBM}$, genetic alterations such as TP53, PIK3CA, KIT, MLH1, and RB1 were detected in both primary $\mathrm{BC}$ and $\mathrm{BCBM}$ in the same patients. Besides our data, other recent findings revealed the existence of metastasis gene signatures expressed by primary tumors [21-23]. Based on these studies, those mutations occurred in the primary carcinoma, and then some of the cell population metastasized to the brain. However, those mutations show that the cells have accumulated a sufficient number of malignant functions to promote expansion of the primary tumor, but not sufficient for forming metastasis [24]. Recent studies suggest that distant metastasis occurs late during the genetic evolution of primary cancer $[25,26]$. We anticipated that if there were discordances between primary $\mathrm{BC}$ and $\mathrm{BCBM}$, genetic alterations could be enriched in $\mathrm{BCBM}$ compared to primary $\mathrm{BC}$. Unexpectedly, the RB1 and SMAD4 mutations were observed more frequently in primary $\mathrm{BC}$ samples, although it should be cautious to make conclusion due to limited number of study population. The tumor suppressor RB1 is often lost by mutation, deletion or transcriptional silencing in may human malignancies [27-29]. RB1 is primarily inactivated in TNBC ( 20\%) [30]. Gupa et al. showed that RB1 loss was associated with unfavorable distant metastasis-free survival in TNBC [31]. The functional loss of RB1 may play a key role in aggressive biology, but its role in metastatic process is unknown. Smad4 is a central mediator of transforming growth factor- $\beta$ (TGF-B) intracellular signaling [32]. Smad 4 mutation is most prevalent in pancreatic and colorectal cancer [32]. Many studies showed that Smad4 alterations were more frequent in advanced cancer and in metastatic cancers $[33,34]$. However, little is known about the expression level of Smad4 or its prognostic significance in breast cancer. Deckers et al. demonstrated that TGF- $\beta$-induced growth inhibition and apoptosis, TGF-ß-induced EMT, and metastasis of breast cancer cells to bone were critically dependent on Smad4 [35]. Fewer frequencies of SMAD4 mutation in BCBM may be attributed that SMAD4 plays a dual role in carcinogenesis, being a tumor suppressor and a tumor promoter in different stages, although further investigations are necessary to confirm these findings.

The p53 tumor suppressor plays a critical role in many cellular pathways controlling cell proliferation, cell survival, and genomic integrity [36]. In breast cancer, the TP53 mutation is associated with more aggressive disease and worse overall survival [37, 38]. Tham et al. showed that TP53 alterations predicted BCBM [39]. However, the contribution of TP53 to BM is poorly understood. According to the various studies, mutations in TP53 occur in $20 \%$ of primary BC and the majority of TP53 mutations are missense substitution $(75 \%)[37,38]$. In the current study, BCBM has an increased frequency of TP53 mutations with distinct properties compared with those found in primary BC. We found a higher frequency of TP53 mutations in BCBM (59.5\% vs. 38.9\%), although it was not statistically significant. In addition, the frequency of complex TP53 mutations was up to $50 \%$ in BCBM. Consistent with our study, a recent study reported by Nigro et al. demonstrated a high frequency (87\%) of TP53 mutations with an over-representation of complex mutations (45\%) [40]. The frequency of complex mutations is reported to be higher in the basal-like subtype of $\mathrm{BC}$ [37]. Indeed, the increased frequency of complex TP53 mutations in brain metastasis might be caused by an increased in basal-like type in BCBM over primary BC (36.6\% vs. 27.8\%). p53 directly influences transcription of genes involved in metastasis by binding to the promoters of various genes known to be involved in regulating cell motility and adhesion, processes that are important for metastasis [41, 42]. Genetic alteration of TP53 not only aids in tumor initiation and progression, but also allows tumors to acquire metastatic facilitators that may suggest that TP53 mutations are a prerequisite for the development of BCBM. A structural and functional analysis of TP53 mutations is needed to develop a comprehensive understanding of BCBM.

The present study has several limitations. Although we applied multiple filters to prioritize genes and pathways of interest, the interpretation of the results should be cautious given the retrospective nature and small sample size of the current study. In addition, variables such as protein-protein interactions, transcriptional repression, and transactivation of other genes should be taken into account for an understanding of BCBM mechanisms. The specific organ microenvironment determines the extent of cancer cell proliferation, angiogenesis, invasion and survival [43]. Histological analysis of resected human brain metastasis revealed tumor cells interdigitated with activated microglia and astrocytes [44-46]. Considering that the organ microenvironment can influence the biology of metastasis, further study on the interactions between tumor cells and the host environment is needed.

In conclusion, we explored paired analysis of mutational profiling between primary BC and BCBM. Major gene mutations may have a role in metastasis to the brain from $\mathrm{BC}$, though it we could not show any difference between primary $\mathrm{BC}$ and $\mathrm{BCBM}$.

\section{MATERIALS AND METHODS}

\section{Patients}

All samples were collected from breast cancer patients who underwent surgical resection at the Samsung Medical Center. The cohort consisted of samples from $18 \mathrm{BC}$ and $42 \mathrm{BM}$ patients. Fifteen matched pairs of primary $\mathrm{BC}$ and $\mathrm{BCBM}$ samples were available. All patients provided written informed consent. This study was performed in accordance with the Declaration of 
Helsinki and approved by Institutional Review Board of Samsung Medical Center (SMC 2013-12-155).

\section{Immunohistochemistry}

Two experienced pathologists reviewed all pathology specimens to determine the following tumor characteristics: histological and nuclear grades, primary tumor size, presence of lymphovascular invasion, multiplicity, and IHC staining for ER, PgR, and HER2. ER and PgR positivity were defined using Allred scores ranging from 3 to 8 based on IHC using antibodies to the ER (Immunotech, Marseille, France) and PgR (Novocastra Laboratories Ltd., Newcastle upon Tyne, UK). HER2 status was evaluated using a specific antibody (Dako, Glostrop, Denmark) and/or fluorescence in situ hybridization (FISH). Grades 0 and 1 for HER2, as assessed by IHC, were defined as a negative result, and grade 3 was defined as a positive result. Amplification of HER2 was confirmed by FISH if HER 2 was rated as $2+$ by IHC.

\section{DNA extraction/RNA extraction}

A total of 60 tissue samples including 18 primary BCs and 42 BCBMs from 45 patients with a tumor cell percentage of more than $75 \%$ (from 4-mm unstained sections) were dissected under a microscope by comparison to an H\&E-stained slide. Genomic DNA was extracted using the Qiagen DNA FFPE Tissue Kit (Qiagen, Hilden, Germany) and total RNA was extracted using the High Pure RNA Paraffin kit (Roche Diagnostics, Mannheim, Germany), according to the manufacturer's instructions. After extraction, we measured DNA and RNA concentration using a spectrophotometer (ND1000; NanoDrop Technologies, Thermo Fisher Scientific, Waltham, MA, USA). Each sample was then quantified using a Qubit fluorometer (Life Technologies, Carlsbad, CA, USA). Samples with less than $10 \mathrm{ng} / \mu \mathrm{L}$ of genomic DNA and less than $50 \mathrm{ng} / \mathrm{uL}$ of total RNA, even after concentration using a SpeedVac concentrator (Thermo Scientific ${ }^{\mathrm{TM}}$, Waltham, MA, USA) were excluded from downstream analysis.

\section{Next-generation sequencing (NGS) using Ion torrent ampliseq cancer panel $v 2$}

Using the Ion Torrent Personal Genome Machine (Ion PGM, Life Technologies, Carlsbad, CA, USA) Cancer Panel v2 (Table S1) after DNA isolation from formalin-fixed, paraffin-embedded (FFPE) samples, we sequenced 2,855 loci from 50 cancer-related genes to identify genetic mutations in 60 samples from $\mathrm{BC}$ patients. Libraries were constructed using the Ion AmpliSeq Panels pool (Life Technologies) with a 10-ng DNA sample per pool. The amplicons were then ligated to Ion Xpress Barcode Adapters and purified. Next, multiplexed bar-coded libraries were enriched by clonal amplification using emulsion PCR on Ion Sphere particles (Ion PGM Template OT2 $200 \mathrm{Kit}$, Life Technologies) and loaded onto an Ion 316 Chip. Massively parallel sequencing was carried out on the Ion PGM using the Ion PGM Sequencing $200 \mathrm{Kit} v 2$. The Ion AmpliSeq Cancer Hotspot Panel v2 (www.lifetechnologies.com) covered hot-spot regions of 50 oncogenes and tumor suppressor genes.

The primary filtering process was carried out using the Torrent Suite v3.6.0 and the Ion Torrent Variant Caller v3.6 software. The pipeline includes signaling processing, base calling, quality score assignment, adapter trimming, read alignment to human genome 19 references, mapping QC, coverage analysis, and variant calling. For variant detection, a minimum coverage of 100 reads must be achieved, and at least $5 \%$ of mutant reads were selected for variants. Variant calls were further analyzed using the ANNOVAR, which included variant filtering and annotation using the COSMIC database, dbSNP build 137, and amino acid change information.

\section{Sample subtype prediction}

PAM50 genes expression was measured on the NanoString nCounter Analysis System (NanoString Technologies, Seattle, WA, USA). The system measures the relative abundance of each mRNA transcript of interest using a multiplexed hybridization assay and digital readouts of fluorescent bar-coded probes that are hybridized to each transcript are created [47]. Intrinsic subtype classification was performed using the PAM50 predictor and was applied to the nearest PAM50 centroid algorithm Bioclassifier to predict the PAM50 subtypes, as described in Parker et al. [48]. To obtain more consistent results, we merged microarray expression data of TCGA breast cancers with our NanoString data after adjusting for batch effects using the ComBat algorithm [49] and applied the nearest PAM50 centroid algorithm Bioclassifier to predict PAM50 subtypes [48]. For all statistical tests, PAM50 subtype prediction was conducted using $\mathrm{R}$ version 3.0.2 (http://www.R-project.org/).

\section{Bioinformatic and statistical analysis for ampliseq}

To obtain results more accurately, the final data were filtered through several steps. In the first step, samples with cytosine deamination were removed. In the second step, false positive site were removed under the following conditions; the coverage $(>100 \mathrm{X})$ and $P$-value $<0.01$. In addition, a minimum threshold of mutant allele fraction (MAF) was taken into account to determine if the variant was real: $>10 \%$ for mutations with a low allele fraction. For the statistical analysis of final variants, read alignments were manually investigated using the Integrative Genomic 
Viewer (http://www.broadinstitute.org/igv/). We filtered out single-nucleotide polymorphisms after manual review of each polymorphism in the Catalogue of Somatic Mutations in Cancer (COSMIC, http://cancer.sanger.ac.uk/ cancergenome/projects/cosmic). We also discarded the Korean-specific germ-line variants rs 1042522 in TP53 and rs 1870377 in KDR. Among the variants that satisfied the filtering criteria described above, variants causing amino acid changes and frameshifts were finally chosen for statistical analysis. Fisher's exact test was used for the analysis of mutations and polymorphic variants separately, to discover variants that were enriched in patients with favorable outcomes. $P$-values $<0.05$ were considered significantly different.

\section{ACKNOWLEDGMENTS AND FUNDINGS}

This work was supported by the Samsung Biomedical Research Institute Grant, No. SBRI SMO1131861.

\section{CONFLICTS OF INTEREST}

The authors have no potential conflicts of interest to declare.

\section{REFERENCES}

1. Lin NU, Bellon JR, Winer EP. CNS metastases in breast cancer. J Clin Oncol. 2004; 22:3608-3617.

2. Al-Shamy G, Sawaya R. Management of brain metastases: the indispensable role of surgery. J Neurooncol. 2009; 92:275-282.

3. Boogerd W, Vos VW, Hart AA, Baris G. Brain metastases in breast cancer; natural history, prognostic factors and outcome. J Neurooncol. 1993; 15:165-174.

4. Gaedcke J, Traub F, Milde S, Wilkens L, Stan A, Ostertag H, Christgen M, von Wasielewski R, Kreipe HH. Predominance of the basal type and HER-2/neu type in brain metastasis from breast cancer. Mod Pathol. 2007; 20:864-870.

5. Fulford LG, Reis-Filho JS, Ryder K, Jones C, Gillett CE, Hanby A, Easton D, Lakhani SR. Basal-like grade III invasive ductal carcinoma of the breast: patterns of metastasis and long-term survival. Breast Cancer Res. 2007; 9:R4.

6. Albiges L, Andre F, Balleyguier C, Gomez-Abuin G, Chompret A, Delaloge S. Spectrum of breast cancer metastasis in BRCA1 mutation carriers: highly increased incidence of brain metastases. Ann Oncol. 2005; 16:1846-1847.

7. Chambers AF, Groom AC, MacDonald IC. Dissemination and growth of cancer cells in metastatic sites. Nat Rev Cancer. 2002; 2:563-572.
8. Nguyen DX, Bos PD, Massague J. Metastasis: from dissemination to organ-specific colonization. Nat Rev Cancer. 2009; 9:274-284.

9. Bos PD, Zhang XH, Nadal C, Shu W, Gomis RR, Nguyen DX, Minn AJ, van de Vijver MJ, Gerald WL, Foekens JA, Massague J. Genes that mediate breast cancer metastasis to the brain. Nature. 2009; 459:1005-1009.

10. Ding L, Ellis MJ, Li S, Larson DE, Chen K, Wallis JW, Harris CC, McLellan MD, Fulton RS, Fulton LL, Abbott RM, Hoog J, Dooling DJ, et al. Genome remodelling in a basal-like breast cancer metastasis and xenograft. Nature. 2010; 464:999-1005.

11. Kim LS, Huang S, Lu W, Lev DC, Price JE. Vascular endothelial growth factor expression promotes the growth of breast cancer brain metastases in nude mice. Clin Exp Metastasis. 2004; 21:107-118.

12. Da Silva L, Simpson PT, Smart CE, Cocciardi S, Waddell N, Lane A, Morrison BJ, Vargas AC, Healey S, Beesley J, Pakkiri P, Parry S, Kurniawan N, et al. HER3 and downstream pathways are involved in colonization of brain metastases from breast cancer. Breast Cancer Res. 2010; 12:R46.

13. Bollig-Fischer A, Michelhaugh SK, Wijesinghe P, Dyson G, Kruger A, Palanisamy N, Choi L, Alosh B, Ali-Fehmi R, Mittal S. Cytogenomic profiling of breast cancer brain metastases reveals potential for repurposing targeted therapeutics. Oncotarget. 2015; 6:14614-14624.

14. Saunus JM, Quinn MC, Patch AM, Pearson JV, Bailey PJ, Nones K, McCart Reed AE, Miller D, Wilson PJ, Al-Ejeh F, Mariasegaram M, Lau Q, Withers T, et al. Integrated genomic and transcriptomic analysis of human brain metastases identifies alterations of potential clinical significance. J Pathol. 2015; 237:363-78.

15. Holstege H, Joosse SA, van Oostrom CT, Nederlof PM, de Vries A, Jonkers J. High incidence of protein-truncating TP53 mutations in BRCA1-related breast cancer. Cancer Res. 2009; 69:3625-3633.

16. Chargari C, Campana F, Pierga JY, Vedrine L, Ricard D, Le Moulec S, Fourquet A, Kirova YM. Whole-brain radiation therapy in breast cancer patients with brain metastases. Nat Rev Clin Oncol. 2010; 7:632-640.

17. Kased N, Binder DK, McDermott MW, Nakamura JL, Huang K, Berger MS, Wara WM, Sneed PK. Gamma Knife radiosurgery for brain metastases from primary breast cancer. Int J Radiat Oncol Biol Phys. 2009; 75:1132-1140.

18. Abboud M, Saghir NS, Salame J, Geara FB. Complete response of brain metastases from breast cancer overexpressing Her-2/neu to radiation and concurrent Lapatinib and Capecitabine. Breast J. 2010; 16:644-646.

19. Zhang Q, Chen J, Yu X, Cai G, Yang Z, Cao L, Hu C, Guo X, Sun J, Chen J. Survival benefit of anti-HER2 therapy after whole-brain radiotherapy in HER2-positive breast cancer patients with brain metastasis. Breast Cancer. 2015.

20. Hicks DG, Short SM, Prescott NL, Tarr SM, Coleman KA, Yoder BJ, Crowe JP, Choueiri TK, Dawson AE, Budd GT, 
Tubbs RR, Casey G, Weil RJ. Breast cancers with brain metastases are more likely to be estrogen receptor negative, express the basal cytokeratin CK5/6, and overexpress HER2 or EGFR. Am J Surg Pathol. 2006; 30:1097-1104.

21. Ramaswamy S, Ross KN, Lander ES, Golub TR. A molecular signature of metastasis in primary solid tumors. Nat Genet. 2003; 33:49-54.

22. van 't Veer LJ, Dai $H$, van de Vijver MJ, He YD, Hart AA, Mao M, Peterse HL, van der Kooy K, Marton MJ, Witteveen AT, Schreiber GJ, Kerkhoven RM, Roberts C, et al. Gene expression profiling predicts clinical outcome of breast cancer. Nature. 2002; 415:530-536.

23. Minn AJ, Gupta GP, Siegel PM, Bos PD, Shu W, Giri DD, Viale A, Olshen AB, Gerald WL, Massague J. Genes that mediate breast cancer metastasis to lung. Nature. 2005; 436:518-524.

24. Chiang AC, Massague J. Molecular basis of metastasis. N Engl J Med. 2008; 359:2814-2823.

25. Yachida S, Jones S, Bozic I, Antal T, Leary R, Fu B, Kamiyama M, Hruban RH, Eshleman JR, Nowak MA, Velculescu VE, Kinzler KW, Vogelstein B, et al. Distant metastasis occurs late during the genetic evolution of pancreatic cancer. Nature. 2010; 467:1114-1117.

26. Shah SP, Morin RD, Khattra J, Prentice L, Pugh T, Burleigh A, Delaney A, Gelmon K, Guliany R, Senz J, Steidl C, Holt RA, Jones $\mathrm{S}$, et al. Mutational evolution in a lobular breast tumour profiled at single nucleotide resolution. Nature. 2009; 461:809-813.

27. Sherr CJ. Cancer cell cycles. Science. 1996; 274:1672-1677.

28. Sharma A, Comstock CE, Knudsen ES, Cao KH, Hess-Wilson JK, Morey LM, Barrera J, Knudsen KE. Retinoblastoma tumor suppressor status is a critical determinant of therapeutic response in prostate cancer cells. Cancer Res. 2007; 67:6192-6203.

29. Burkhart DL, Sage J. Cellular mechanisms of tumour suppression by the retinoblastoma gene. Nat Rev Cancer. 2008; 8:671-682.

30. Comprehensive molecular portraits of human breast tumours. Nature. 2012; 490: 61-70.

31. Gupta GP WY, Rogers K, Akram M, Gucalp A, Traina T, Powell SN, Brogi E, Ho AY et al. . Intact RB1 pathway is associated with favorable distant metastasis-free survival in triple negative breast cancer. Int J Radiat Oncol Biol Phys. 2012; 84:S140.

32. Miyaki M, Kuroki T. Role of Smad4 (DPC4) inactivation in human cancer. Biochem Biophys Res Commun. 2003; 306:799-804.

33. Miyaki M, Iijima T, Konishi M, Sakai K, Ishii A, Yasuno M, Hishima T, Koike M, Shitara N, Iwama T, Utsunomiya J, Kuroki T, Mori T. Higher frequency of Smad4 gene mutation in human colorectal cancer with distant metastasis. Oncogene. 1999; 18:3098-3103.
34. Maitra A, Molberg K, Albores-Saavedra J, Lindberg G. Loss of Dpc4 expression in colonic adenocarcinomas correlates with the presence of metastatic disease. Am J Pathol. 2000; 157: 1105-1111.

35. Deckers M, van Dinther M, Buijs J, Que I, Lowik C, van der Pluijm G, ten Dijke P. The tumor suppressor Smad4 is required for transforming growth factor beta-induced epithelial to mesenchymal transition and bone metastasis of breast cancer cells. Cancer Res. 2006; 66:2202-2209.

36. Vogelstein B, Lane D, Levine AJ. Surfing the p53 network. Nature. 2000; 408:307-310.

37. Pharoah PD, Day NE, Caldas C. Somatic mutations in the p53 gene and prognosis in breast cancer: a meta-analysis. Br J Cancer. 1999; 80:1968-1973.

38. Olivier M, Langerod A, Carrieri P, Bergh J, Klaar S, Eyfjord J, Theillet C, Rodriguez C, Lidereau R, Bieche I, Varley J, Bignon Y, Uhrhammer N, et al. The clinical value of somatic TP53 gene mutations in 1,794 patients with breast cancer. Clin Cancer Res. 2006; 12:1157-1167.

39. Tham YL, Sexton K, Kramer R, Hilsenbeck S, Elledge R. Primary breast cancer phenotypes associated with propensity for central nervous system metastases. Cancer. 2006; 107:696-704.

40. Lo Nigro C, Vivenza D, Monteverde M, Lattanzio L, Gojis O, Garrone O, Comino A, Merlano M, Quinlan PR, Syed N, Purdie CA, Thompson A, Palmieri C, et al. High frequency of complex TP53 mutations in CNS metastases from breast cancer. Br J Cancer. 2012; 106:397-404.

41. Wei CL, Wu Q, Vega VB, Chiu KP, Ng P, Zhang T, Shahab A, Yong HC, Fu Y, Weng Z, Liu J, Zhao XD, Chew JL, et al. A global map of p53 transcription-factor binding sites in the human genome. Cell. 2006; 124:207-219.

42. Powell E, Piwnica-Worms D, Piwnica-Worms H. Contribution of p53 to metastasis. Cancer Discov. 2014; 4: 405-414.

43. Fidler IJ, Balasubramanian K, Lin Q, Kim SW, Kim SJ. The brain microenvironment and cancer metastasis. Mol Cells. 2010; 30: 93-98.

44. Seike T, Fujita K, Yamakawa Y, Kido MA, Takiguchi S, Teramoto N, Iguchi H, Noda M. Interaction between lung cancer cells and astrocytes via specific inflammatory cytokines in the microenvironment of brain metastasis. Clin Exp Metastasis. 2011; 28: 13-25.

45. Fitzgerald DP, Palmieri D, Hua E, Hargrave E, Herring JM, Qian Y, Vega-Valle E, Weil RJ, Stark AM, Vortmeyer AO, Steeg PS. Reactive glia are recruited by highly proliferative brain metastases of breast cancer and promote tumor cell colonization. Clin Exp Metastasis. 2008; 25:799-810.

46. Mendes O, Kim HT, Lungu G, Stoica G. MMP2 role in breast cancer brain metastasis development and its regulation by TIMP2 and ERK1/2. Clin Exp Metastasis. 2007; 24:341-351. 
47. Sohn I, Kim J, Jung SH, Park C. Gradient lasso for Cox proportional hazards model. Bioinformatics. 2009; 25:1775-1781.

48. Parker JS, Mullins M, Cheang MC, Leung S, Voduc D, Vickery T, Davies S, Fauron C, He X, Hu Z, Quackenbush JF, Stijleman IJ, Palazzo J, et al. Supervised risk predictor of breast cancer based on intrinsic subtypes. J Clin Oncol. 2009; 27:1160-1167.
49. Johnson WE, Li C, Rabinovic A. Adjusting batch effects in microarray expression data using empirical Bayes methods. Biostatistics. 2007; 8:118-127. 